\title{
Letramento crítico e ensino comunicativo: lacunas e interseções
}

\author{
Critical Literacy and Communicative \\ Teaching: gaps and intersections
}

Andréa Machado de Almeida Mattos*

UFMG

Kátia Modesto Valério**

UFF

RESUMO: O presente artigo pretende suscitar reflexôes acerca dos pontos de contato e de distanciamento entre o ensino comunicativo, abordagem amplamente difundida para o ensino de língua inglesa no Brasil, e o letramento crítico, proposta recentemente feita pelas novas Orientaçōes Curriculares para o Ensino Médio (OCEM). Primeiramente, faremos um levantamento das tradiçóes teóricas que dão origem às duas concepções de ensino, abordando seus principais conceitos. Depois, discutiremos questôes que aproximam as duas abordagens, assim como aquelas que tendem a distanciá-las. Ressaltamos que as duas concepções de ensino, embora distintas em várias de suas propostas, não são incompatíveis, mas, sim, complementares. Ofereceremos, por fim, um exemplo de uma atividade integrada que tem por objetivo conciliar os anseios dessas duas concepções.

PALAVRAS-CHAVE: abordagem comunicativa, letramento crítico, integração.

ABSTRACT: The objective of this paper is to foster reflections on the similarities and differences between the Communicative Approach, a well-known method for English language teaching in Brazil, and Critical Literacy, the latest suggestion made by the new Orientaçoes Curriculares para o Ensino Médio (OCEM). First, we will address the theoretical traditions that give origin to the two teaching approaches, explaining their main concepts. Then, we will discuss the similarities between the two approaches, as well as their main differences. We claim that the two teaching approaches, however different in their proposals, are not incompatible, but complementary. Finally, we suggest an example of an integrated activity that aims to reconcile the objectives of the two approaches.

KEYWORDS: Communicative Approach, Critical Literacy, integration.

\footnotetext{
* andreamattosufmg@gmail.com

** katia_valerio@yahoo.com.br
} 
Choices that teachers make in classrooms are always, in part, decisions about what students and, hence, the nation should become.

(CERVETTI; PARDALES; DAMICO, 2001)

\section{Introdução}

Este $\operatorname{artigo}^{1}$ pretende apontar caminhos, levantar possibilidades e propiciar discussões acerca do ensino de línguas estrangeiras (LE) no âmbito da escola regular no Brasil. Inspiradas pelas novas Orientaçōes Curriculares para o Ensino Médio (OCEM), pretendemos, buscando as interseções entre o Letramento Crítico (LC) e o Ensino Comunicativo (EC) e sugerindo estratégias para se preencher as lacunas entre as duas vertentes pedagógicas, colocar em evidência a relevância do ensino do idioma estrangeiro para a formação do aluno-cidadão.

A proposta da abordagem comunicativa pretendia revolucionar o ensino de línguas estrangeiras. A partir dela, a língua não mais seria vista como uma estrutura, mas como um meio de se criar significados. O processo de aprendizagem de uma LE implicaria, pois, não no conhecimento de regras gramaticais, mas na capacidade de se fazer uso dessas regras com propriedade e eficiência para determinados fins comunicativos. No entanto, após mais de 30 anos da implementação do ensino comunicativo no Brasil (ALMEIDA FILHO, 2001), regras gramaticais - pior: em muitos casos, apenas regras gramaticais - continuam a ser ensinadas na grande maioria das escolas regulares. A aprendizagem por meio do uso autêntico e significativo da língua-alvo, por diversos motivos, ainda não se sedimentou no cenário nacional. A distância entre os aprendizes brasileiros e situações reais de comunicação na língua-alvo; a conveniência do terreno seguro e com menores demandas da abordagem estrutural; as deficiências comunicativas dos próprios professores no uso do idioma; a falta de disposição de instituiçôes para investimento na implementação de um currículo comunicativo; turmas excessivamente numerosas e a conduta naturalmente decorrente do ambiente de sala de aula tradicional, com sua disposição de assentos; o pouco tempo destinado à LE na grade curricular; a menos valia dos sujeitos envolvidos no processo educativo somada à descrença na relevância da disciplina estão entre algumas das razões que podemos levantar

${ }^{1}$ Uma versão simplificada deste trabalho foi apresentada durante o VI Congresso Internacional da ABRALIN, em João Pessoa-PB, em março de 2009. 
para a não consolidação do ensino comunicativo de LE, em nenhuma de suas formas, ${ }^{2}$ na escola regular.

Por outro lado, no cenário internacional, a abordagem comunicativa vem ganhando novas feições. O movimento pendular resultante do declínio da versão mais forte não trouxe a cabo a proposta do ensino comunicativo. Pelo contrário, em sua chamada 'versão fraca', incorpora a instrução de aspectos formais (fonológicos, lexicais, gramaticais e pragmalinguísticos) da língua-alvo (ELLIS, 2005), o que é visto como um avanço para uma abordagem cujas contribuições para a aprendizagem do idioma continuam sendo o foco de diversos estudos na área. Além disso, o projeto comunicativo recebeu a indicação por parte das políticas educacionais adotadas por países como Japão, Taiwan (SAVIGNON, 2001; 2007) e Brasil (MENEZES DE SOUZA; MONTE-MÓR, 2006).

Desde o início da era comunicativa, em todas as realizaçôes dessa abordagem, destaca-se a centralidade do papel do aluno no processo de aprendizagem, suas necessidades e interesses (SAVIGNON, 2001). Dentro desse paradigma, para que se possa pensar em uma política nacional para o ensino de uma língua estrangeira, é vital que se tenha em mente os aprendizes para os quais essa política está voltada. No entanto, como se pode fazer isso se dentro do Brasil há tantos Brasis? Talvez nessa incomensurável diversidade esteja a resposta que buscamos, pois tal diversidade não constitui empecilho, mas, sim, um recurso, um bem inestimável para uma sociedade que se busca plural e igualitária. Dentro das necessidades em nível nacional desse aluno de mil rostos, está aquela de se saber capaz de agir e transformar a realidade e de perceber indivíduos de diferentes feições como parceiros em termos de atuação e contribuição para uma sociedade mais justa e plural. A valorização das

\footnotetext{
${ }^{2}$ Referimo-nos aqui às duas versões principais da abordagem comunicativa: a versão forte e a versão fraca. Em sua versão "fraca", a abordagem comunicativa advoga a importância de se criar oportunidades para que os alunos utilizem a língua alvo em atividades com fins comunicativos que podem estar integradas a um programa mais abrangente para o ensino da língua, envolvendo também o uso de outros tipos de atividades. Em sua versão "forte", a abordagem comunicativa advoga que só é possível adquirir a língua-alvo por meio da comunicação. Assim, não se trata mais de desenvolver atividades que promovam o uso da língua-alvo para ativar um conhecimento sistêmico já existente, mas o objetivo passa a ser o desenvolvimento do próprio sistema linguístico por meio da comunicação. Segundo Richards e Rodgers (1986), a versão fraca se caracteriza como uma abordagem que objetiva "aprender para usar" a língua, ao passo que a versão forte objetiva "usar [a língua] para aprendê-la” (p. 66).
} 
diferenças e a troca de significados entre elas são passos fundamentais para a formação do cidadão consciente, objetivo derradeiro do processo educativo. Como propõem as novas Orientações Curriculares para o Ensino Médio, o letramento crítico, e as ideias advindas das teorias de novos letramentos e multiletramentos (COPE; KALANTZIS, 2000; LANKSHEAR; KNOBEL, 2003), vem, nesse contexto, constituir proposta pedagógica capaz de apontar alternativas para a reconstrução da identidade desse aluno que se quer cidadão. O letramento crítico e a abordagem comunicativa parecem, nesse contexto, abrigar algumas das respostas para que possamos nos aproximar de uma política nacional viável para o ensino de línguas estrangeiras. Mas como conciliar campos epistemológicos com tradições, objetivos e concepções de língua e de aprendizagem tão distintas? Para tentar responder a essa pergunta, nos debruçamos, a seguir, sobre alguns dos aspectos das duas abordagens para então traçarmos alguns paralelos entre elas.

\section{Tradições teóricas}

O ensino comunicativo surgiu no início da década de 70 (RICHARDS; ROGERS, 1986) em resposta à insatisfação com abordagens mais formais para dar conta do ensino de línguas estrangeiras diante das necessidades crescentes de um mundo que ensaiava seus primeiros passos rumo à globalização (McDONOUGH; SHAW, 2003; SAVIGNON, 2001). Para viabilizar a comunicação intercultural, o ensino não mais poderia ficar restrito à competência linguística priorizada pelas abordagens em voga naquele momento. A abordagem comunicativa surgiu a partir daí, respaldada na visão instrumental da língua proposta por filósofos da linguagem, como Austin (1962) e Searle (1969; 1971), e na concepção de língua como potencial de significação da linguística funcional ou sistêmica (HALLIDAY, 1978). Sedimentou-se também no conceito de competência comunicativa proposto pela antropologia-linguística (HYMES, 1972), em resposta à ótica mentalista formal de Noam Chomsky.

Diferentemente da vocação mercadológica da revolução comunicativa, as bases do letramento crítico se sustentam em valores revolucionários (CERVETTI; PARDALES; DAMICO, 2001; NORTON, 2007). Desenhado a partir dos pressupostos da teoria crítica social, o LC compreende o texto como um produto de forças ideológicas e sociopolíticas, e um "local de luta, negociação e mudança” (NORTON, 2007, p. 6). Também se constitui a partir da pedagogia crítica de Paulo Freire e sua visão da linguagem como elemento libertador. O desenvolvimento da consciência crítica 
pretendido por Freire, em resposta à opressão e exploração econômica da população agrária no Brasil, possibilitaria ao indivíduo "recriar suas identidades e realidades sociopolíticas por intermédio de processos de significação e de suas ações no mundo" (CERVETTI; PARDALES; DAMICO, 2001). A pósmodernidade veio reforçar essa concepção inclusiva; dessa tradição, o letramento crítico incorpora a noção de discursos ou sistemas discursivos como "formas institucionalizadas de pensamento [que] definem o que pode e o que não pode ser dito a respeito de um determinado tópico" (ANDREOTTI, 2006, p. 17), frutos da interseção dos sujeitos e do contexto sociopolítico em que se inserem, e a partir dos quais constroem significados. Comprometido com valores como justiça e luta contra as desigualdades, o letramento crítico pretende mudar a sociedade, promovendo a inclusão social de grupos marginalizados (ALFORD, 2001) a partir da "expansão do escopo de identidades sociais em que as pessoas possam se transformar" (JORDÃO, 2002, p. 3).

A língua é tida como um recurso dinâmico para a criação de significados por ambas as abordagens, mas, no letramento crítico, enfoca-se a dimensão socio-histórica desses significados. Visando ao desenvolvimento da competência comunicativa, o EC se ocuparia do teor psico-social da comunicação, enquanto o LC se debruça sobre seu caráter ideológico, sendo o desenvolvimento da consciência crítica seu principal objetivo (cf. QUADRO 1). No LC a língua assume um caráter libertador, pois é por intermédio do controle e da crítica aos significados imbuídos no discurso e pela criação de um discurso alternativo que se daria a construção do cidadão consciente (CERVETTI; PARDALES; DAMICO, 2001). Em outras palavras, na abordagem comunicativa o aluno aprende a língua estrangeira para a interpretação, expressão e negociação de significado (SAVIGNON, 2001); já no letramento crítico, ele aprende língua (materna e / ou estrangeira) para transformar a si mesmo e a sociedade, se assim lhe convier. Para o ensino comunicativo (EC), a língua é um instrumento de socialização; e para o letramento crítico (LC), ela é, em última análise, um instrumento de poder e de transformação social. 


\section{QUADRO 1}

Tradições teóricas, objetivos e compreensão do objeto de estudo no Ensino Comunicativo e no Letramento Crítico

\begin{tabular}{l|l|l}
\cline { 2 - 3 } & Ensino Comunicativo & Letramento Crítico \\
\hline Origens & $\begin{array}{l}\text { Filosofia da linguagem } \\
\text { Antropologia linguística } \\
\text { Linguística sistêmica }\end{array}$ & $\begin{array}{l}\text { Teoria social crítica } \\
\text { Pedagogia Crítica } \\
\text { Pós-estruturalismo }\end{array}$ \\
\hline Objetivos & $\begin{array}{l}\text { Desenvolvimento da } \\
\text { competência comunicativa } \\
\text { (usar para aprender e } \\
\text { aprender para usar) }\end{array}$ & $\begin{array}{l}\text { Desenvolvimento da } \\
\text { consciência crítica } \\
\text { (aprender para transformar) }\end{array}$ \\
\hline Visão de Língua & $\begin{array}{l}\text { Recurso dinâmico para a } \\
\text { criação de significados }\end{array}$ & $\begin{array}{l}\text { Instrumento para a } \\
\text { reconstrução social }\end{array}$ \\
\hline Implementação & $\begin{array}{l}\text { Promovido por atividades } \\
\text { que envolvem comunicação real. }\end{array}$ & $\begin{array}{l}\text { Promovido por um diálogo } \\
\text { que elicie a crítica social. }\end{array}$ \\
\hline
\end{tabular}

\section{Conceitos e preceitos}

Apesar de díspares em relação às tradições teóricas das quais são oriundas, as duas abordagens compartilham alguns de seus preceitos e conceitos mais básicos. Dentre eles, destacaremos aqui o protagonismo do aprendiz e a centralidade da heterogeneidade. Focalizaremos também alguns princípios e conceitos que, servindo de contato entre as duas abordagens, constituem-se em excelentes veios para transposição didática, como a noção de gênero textual, de autenticidade, os multiletramentos, assim como algumas práticas pedagógicas disseminadas por abordagens voltadas para o desenvolvimento da consciência linguística.

\section{Protagonismo do Aprendiz}

LC e EC compartilham um veio norteador - o protagonismo do aprendiz. No cenário social da sala de aula, as regras de conduta que delegam ao professor o monopólio do saber e do controle das regras interacionais, as quais incluem o comando do sistema de troca de turnos, deram lugar à negociação de saberes decorrente de uma visão mais flexível dos papéis desempenhados na sala de aula (WIDDOWSON, 1987). De elemento passivo no processo de aprendizagem, o aluno passou a ocupar a ribalta desse cenário social, tendo sua ativa participação no próprio processo de aprendizagem reconhecida e incentivada. 
Para o EC, essa flexibilidade de papéis vem atuar como elemento facilitador do processo de aprendizagem, pois permite ao aprendiz tomar iniciativas, exercitar sua intuição e criatividade e sentir-se mais confiante para engajar-se em atividades comunicativas em sala de aula, possibilitando-lhe, ainda, apropriar-se de seu processo de aprendizagem. Além disso, o direcionamento do foco das atividades de sala de aula, tradicionalmente voltado para o código, para o aprendiz, levou à consideração de sua bagagem cultural - suas necessidades, propósitos e expectativas são o patamar do qual se deve partir (SAVIGNON, 2001; ALMEIDA FILHO, 2001). Ou seja, para o EC, a consideração dos esquemas mentais trazidos pelos indivíduos impõese como necessidade pedagógica que viabiliza o processo de aprendizagem.

Para o LC, o tipo de educação promovida pela sala de aula tradicional está a serviço da perpetuação das relações de poder já existentes, promovendo a conformação ao privar o indivíduo de oportunidades para questionamentos. O LC tem objetivo inverso ao da educação tradicional, pois promove o empoderamento do aprendiz, que é levado a apropriar-se de seu próprio processo educacional. Somente esse tipo de envolvimento pode conduzi-lo à reflexão crítica acerca de sua cultura e cotidiano, levando-o, assim, ao questionamento de sua condição (FREIRE, 1970). Portanto, somente a sala de aula democrática e humanizada poderia suscitar as reflexões preconizadas pelo LC, que, partindo da localização social e histórica do aprendiz, busca a compreensão dos sistemas discursivos com os quais se depara.

As duas abordagens, assim, se mostram construtivistas, já que ambas visam à construção do conhecimento a partir daquilo que o aprendiz traz para o processo de aprendizagem. Portanto, a centralidade do papel do aprendiz vem requerer, de ambas as abordagens, a consideração das necessidades do aprendiz e da diversidade do cabedal trazido por cada indivíduo. A visão do aluno como sujeito sócio-histórico portador de bens culturais (BOURDIEU, 1996) inestimáveis, por parte do LC, e a necessidade de se partir do conhecimento prévio do aprendiz como condição para torná-lo um comunicador eficiente, no EC, têm como implicação lógica e necessária a incorporação do conceito de heterogeneidade.

\section{Heterogeneidade}

Tanto o ensino comunicativo quanto o letramento crítico em uma língua estrangeira passam, então, pela percepção da coexistência da diversidade cultural que encontra expressão em sistemas linguístico-culturais distintos nas 
comunidades de fala, tanto aquelas da língua materna quanto as da língua estrangeira. Assim como o EC propõe um olhar distanciado, não partidário, com relação aos contrastes interculturais, o LC quer o mesmo distanciamento com relação às variedades linguísticas, advogando a limitação do papel da norma às funçôes sociais que pode cumprir. Relacionando as formas-padrão apenas aos contextos nos quais é utilizada, sua superioridade pode ser, então, desmistificada, desconstruída, possibilitando a compreensão de que, em qualquer cultura, coexistem diferentes formas de agir. Por isso, o sistema linguístico-cultural homogêneo não deve se impor como alternativa única. Ele deve ser identificado, dominado e compreendido como elemento transformador, o que pode ser feito por intermédio da observação e análise desse sistema em comparação a outros sistemas linguísticos e socioculturais até então tidos como 'desvios'. Desse modo, esse sistema, antes visto como homogêneo e único, estaria a serviço da educação para a cidadania, que compreende os outros sistemas como instrumentos de socialização e da expressão de uma identidade.

Portanto, seria compatível com as duas abordagens em tela, o contato do aprendiz com sistemas alternativos também das comunidades de fala da língua-alvo. Semelhanças e contrastes poderiam, então, ser identificados não só em relação às duas línguas e culturas mas também às diferenças discursivas e socioculturais que ganham reflexo nos dois idiomas. A consciência dessa heterogeneidade como meio de expressão para a diversidade se coaduna à pragmática intercultural. Essa área da sociolinguística aplicada não parte do princípio de que o aprendiz deva se adequar ao modus operandi da comunidade de fala alvo (BOXER, 2002), mesmo porque este comporta uma multiplicidade de formas. Ela preconiza, sim, que as diversas linhas de conduta sejam reconhecidas e respeitadas para que interaçôes entre membros de diferentes culturas possam ser bem-sucedidas. O desenvolvimento da consciência intercultural (CRAWSHAW, 2005), então, se dá por intermédio do conhecimento e da compreensão das diferenças, sem, no entanto, abrir-se mão de valores, exatamente como propõem as OCEM (MENEZES DE SOUZA; MONTE-MÓR, 2006); muito pelo contrário, pois o Eu só se constrói em oposição ao Outro. Portanto, só a percepção de outros valores, não como desvios, mas como próprios de nossas culturas, pode nos dar melhor noção da heterogeneidade presente em nossa própria identidade.

\section{Gênero Textual}

Como vimos, a seleção de textos que retratem um mesmo sistema homogêneo, imposto por um segmento social, reforçaria a ideia de ser esse o 
único sistema, por assim dizer, o que confinaria outros modos de expressão a um gueto denominado 'desvio', o que é indesejável tanto para o LC quanto para o EC. Portanto, faz-se necessário que se atente às variáveis situacionais que determinam as condições de produção dos textos e o próprio texto. $\mathrm{O}$ texto escrito, insumo usual para as aulas de língua estrangeira, passa a compartilhar a ribalta não só com a modalidade oral mas também com modalidades híbridas ou multimodais (SILVER, 1997), como é o caso das salas de bate-papo na internet. $\mathrm{O}$ canal de que se faz uso para a comunicação implica a implementação de diferentes processos fisiológicos e sofre influências de diversos tipos; dentre elas, o tempo que o enunciador dispõe para se fazer entender. A escrita, via de regra, permite a edição do texto e sua consequente adequação à norma, o que poderia inviabilizar a observação da diversidade linguística que caracteriza a oralidade de um modo geral, por exemplo.

Para que tenha noção da miríade de modos de expressão disponíveis para ele, o aprendiz deve ter a oportunidade de examinar textos que envolvam variados graus de planejamento, diversos níveis de formalidade, assim como diferentes números de participantes em sua construção, pois todas essas dimensōes interagem entre si para caracterizar as situaçôes das quais florescem os textos (CELCE-MURCIA; OLSHTAIN, 2000). A partir daí, cada interseção identificada entre essas instâncias comporta variados gêneros, aos quais o aprendiz pode ter acesso. A noção de gênero textual vem nesse momento constituir excelente veio para a transposição didática da ideia de heterogeneidade para a sala de aula de língua estrangeira, sendo capaz de estabelecer um elo entre o LC e o EC. Gêneros surgem a partir das necessidades de uma comunidade discursiva (SWALES, 1990) e, portanto, é à luz dos valores, expectativas e prioridades dessa comunidade que os textos são produzidos e interpretados. Dado seu estatuto de ação social, gêneros conduzem à consideração do contexto sociocultural que os originou e os mantém, nos colocando frente a frente com a realidade social que ele comunica (BHATIA, 1993). A adoção do conceito de gênero pode viabilizar a abordagem de diferentes níveis de análise textual, pois esse conceito estabelece o elo entre as dimensões textual, social e política dos textos (JOHNS et al, 2006; HAMMOND; DEREWIANKA, 2001; PALTRIDGE, 2001).

A adoção da noção de gênero como parâmetro permite o processamento textual ascendente, comportando o estudo de padrões gramaticais, fonológicos, lexicais, relacionados ao registro em questão, necessário para o desenvolvimento da competência linguística. Gêneros textuais, contando com os esquemas mentais formais do aprendiz, promovem o exame de padrôes retóricos, contribuindo, 
dessa forma, para sua competência discursiva. A análise do contexto sociocultural que engendrou um determinado texto viabiliza também a identificação da função comunicativa que cumpre, informando o aprendiz para o desenvolvimento de sua competência sociolinguística. Desse modo, essa noção parece ajustar-se perfeitamente aos objetivos do EC; no entanto, para servir às interpelações propostas pelo LC, a análise de um texto requer mais um passo em direção aos esquemas mentais de conteúdo trazidos pelo aprendiz no sentido de permitir-lhe uma visão ainda mais ampla do texto - o exame de seu caráter ideológico. McLaughlin e DeVoogd (2004, p. 14) afirmam que o letramento crítico considera "os leitores como participantes ativos no processo de leitura", permitindo que os leitores deixem de "aceitar passivamente a mensagem do texto para questionar, examinar e desafiar as relações de poder" expressas pelo texto. Esses autores concordam com Cervetti, Pardales e Damico (2001, p. 6), quando dizem que o letramento crítico "promove a reflexão, a transformação e a ação.” A formação de cidadãos críticos envolve, pois, necessariamente, a identificação do segmento social cujas vozes encontram representação no texto e a reflexão sobre sua serventia, com vistas à mudança social.

A noção de gênero textual parece, então, ser capaz de suprir as demandas das duas abordagens (EC e LC), calibrando a heterogeneidade por elas proposta e servindo de norte não só para a elaboração de currículos em diversos contextos educacionais (BAX, 2006) como também para a prática diária do profissional de educação, constituindo-se em poderoso aliado para a seleção e adequação de material didático.

\section{Autenticidade}

É no processo de seleção e adequação do material didático que surge naturalmente a preocupação com outro conceito - a autenticidade. Compreendido por Nunan (1999, p. 27) como "amostras de língua oral ou escrita que não tenham sido escritos especificamente com o propósito de se ensinar uma língua”, o material autêntico tem sido descrito no EC como o insumo mais eficiente para preparar o aprendiz para lidar com situações reais de comunicação. Apesar da dificuldade da utilização legal de textos autênticos (CRAWFORD, 2002), esses parecem ser os únicos capazes de veicular determinados aspectos de textos genuínos, sobretudo os orais (NUNAN, 1999). Embora a adaptação normalmente sofrida pelos textos para torná-los palatáveis em termos pedagógicos, sociais, éticos ou até mesmo comerciais não pareça ser ideal para o EC, a autenticidade já começa a ser percebida como o 
processo de tornar a interação autêntica para os que dela participam, independentemente dos materiais utilizados para tal (SVALBERG, 2007).

A autenticidade para o LC é ainda mais premente, impondo-se como fator indispensável para sua realização. Adaptações são frutos de abstrações que serviriam senão à homogeneidade que desfiguraria o produto de uma ação social. A compreensão da língua como prática social estaria, pois, vinculada a sua gênese em um determinado contexto, uma vez que somente esse contexto poderia viabilizar a compreensão das relações de poder por ela retratadas, mantidas e / ou construídas. Textos, para o LC, devem permitir ao aluno compreender a ideologia e as regras socioculturais, discursivas e linguísticas de diferentes substratos sociais em diversas situaçóes. Para ilustrar essa diversidade, podemos citar as diferentes regras de conduta que norteiam o comportamento linguístico de um indivíduo em família, em seu trabalho, e, ainda, entre amigos no clube, por exemplo. Como se poderia compreender, então, a utilização de dados inventados para informar o aluno a respeito da realização discursiva de diferentes segmentos sociais? Como poderia um autor criar uma interação entre companheiros de 'pelada', por exemplo, sem impor sobre ela seus próprios padrōes linguísticos, culturais e ideológicos e suas próprias perspectivas de interpretação?

Embora a busca pela autenticidade pareça constituir mais um ponto de contato entre as duas abordagens consideradas, sua implementação não figura entre os avanços no ensino de línguas estrangeiras que se possam vislumbrar. No cenário atual, a autenticidade se rende ao mercado e às leis internacionais de direitos autorais. Mais rígidas que as brasileiras, ${ }^{3}$ as restrições ao uso de textos

${ }^{3} \mathrm{O}$ uso de trechos de textos autênticos para fins didáticos não constituiria ofensa já que, de acordo com o parágrafo 46, inciso VII da lei de direito autoral de $\mathrm{n}^{\circ} 9.610$, de 19 de fevereiro de 1998, "Não constitui ofensa aos direitos autorais (...) a reprodução, em quaisquer obras, de pequenos trechos de obras preexistentes, de qualquer natureza, ou de obra integral, quando de artes plásticas, sempre que a reprodução em si não seja o objetivo principal da obra nova e que não prejudique a exploração normal da obra reproduzida nem cause um prejuízo injustificado aos legítimos interesses dos autores". No entanto, como o artigo $5^{\circ}$ da Constituição Federal garante a aceitação dos tratados e acordos internacionais como lei interna, deve-se considerar o artigo $9^{\circ}$ da Convenção de Berna, segundo o qual "Os autores de obras literárias e artísticas protegidas pela presente Convenção gozam do direito exclusivo de autorizar a reprodução de suas obras por qualquer procedimento e sob qualquer forma". (cf.: http://www.abdr.org.br/ legis.html\#BERNA, http://www.cultura.gov.br/site/categoria/legislacao/leis/ e http:/ /www.youtube.com/watch?v=AZuR0-Gyusw\&feature=related). 
e imagens para fins pedagógicos protelam os avanços que tanto o EC quanto o LC propõem.

\section{Multiletramentos}

Como o EC surgiu a partir da necessidade do funcionamento de indivíduos e instituições em um mundo globalizado, a desenvoltura comunicativa em uma sociedade informatizada e altamente digitalizada (LANKSHEAR; KNOBEL, 2003) é para ele uma preocupação pertinente. Sabe-se que a comunicação mediada por computador constitui instrumento para o desenvolvimento da competência discursiva com relação aos gêneros digitais na cultura-alvo. Em suas formas assíncronas, como o e-mail e os blogs, e síncronas, como as salas de bate-papo e as conversas ou reunióes com voz e vídeo a partir de programas disponíveis na internet, como o Skype e o MSN, possibilita ao aprendiz se comunicar de forma significativa e autêntica (SOKOLIK, 2001), estratégia central para o desenvolvimento da competência comunicativa. Como já ressaltamos, no ambiente digital a comunicação é multimodal, isto é, a informação é fornecida não apenas em forma de texto escrito mas também por meio de outros elementos ditos multimodais. Segundo Silver (1997), elementos multimodais podem incluir textos, fotografias, imagens e gráficos, clips de vídeo e som, e até elementos de animação. No entanto, a multimodalidade e multidimensionalidade dos gêneros digitais impuseram à abordagem comunicativa a urgência da compreensão de que a construção de sentido se dá a partir de um todo, como propõe Morin (2000), não comportando fragmentação ou linearidade. Refuta-se, então, a organização curricular conteudista, compartimentada no desenvolvimento de cada uma das quatro habilidades (leitura, escrita, compreensão e produção oral) de modo isolado. Estas dão lugar ao desenvolvimento integrado das habilidades necessárias para a comunicação em um sentido mais amplo em atividades que sejam significativas para o aluno.

O letramento crítico visa à inclusão do indivíduo no mundo. No entanto, para efetivamente fazer parte da sociedade contemporânea globalizada e atuar dentro e sobre ela, o aprendiz deve ter acesso às diferentes modalidades e dimensões da linguagem da era tecnológica atual. O leitor-cidadão que se pretende formar pode circular pela linguagem visual, digital, multicultural e crítica, cotidianamente. No entanto, faz-se urgente tal formação, pois a velocidade e facilidade de acesso às informações possibilitadas pelas inovações tecnológicas aumentam em um ritmo espantoso a lacuna entre o letrado e o iletrado, que se vê cada vez mais distante da sociedade que quer integrar. 
Assim, o letramento multimodal (COPE; KALANTZIS, 2000) faz-se vital ferramenta para as aspiraçôes de ambas as abordagens, pois torna real a possibilidade de integração entre membros de diferentes comunidades de fala, estabelecendo novas comunidades discursivas que independem de fronteiras geopolíticas (SAVIGNON, 2007). O domínio da multimodalidade impõe-se, então, como elemento facilitador da mobilidade do indivíduo, capaz de implementar um "diálogo de culturas [... onde] cultura é tida como a concentração de todos os outros significados (social, espiritual, lógico, emocional, moral, estético) da existência humana” (BIBLER, 1991, apudSAVIGNON, 2007, p. 212).

\section{Consciência Linguística}

Surgida na década de 70 como proposta curricular para a constituição de uma disciplina que estabelecesse o contato entre o ensino de língua materna e o ensino de línguas estrangeiras no currículo da escola regular no Reino Unido (HAWKINS, 1999), a consciência linguística (language awareness) vem se consolidando como campo de estudos e de prática capaz de firmar elos entre o EC e o LC.

Desde o início da década de 90, a consciência linguística vem se instalando no ensino comunicativo, com inúmeros estudos acerca do papel facilitador que o conhecimento consciente pode assumir no processo de aprendizagem de línguas (SVALBERG, 2007). Na chamada versão fraca da abordagem comunicativa, o braço cognitivo da consciência linguística vem tomando corpo por intermédio do debate sobre o foco na forma. A reflexão, traço característico de metodologias voltadas para o desenvolvimento da consciência linguística, tem, nessa versão, papel primordial, pois alimenta a metaconversa que medeia o processo de apropriação necessário à aprendizagem de uma língua estrangeira (TOCALLI-BELLER; SWAIN, 2005). Além disso, teorias de aprendizagem compatíveis com o EC passaram a considerar variáveis individuais para a aquisição de um idioma e estratégias para lidar com essas variáveis no sentido da otimização da aprendizagem e da formação do aprendiz autônomo. A partir da década de 80, tal preocupação traz, para o cenário do ensino de línguas estrangeiras, a reflexão como meio de desenvolvimento do conhecimento do aprendiz sobre seu próprio processo de aprendizagem. Voltada para o autoconhecimento, a reflexão, aqui, reveste-se de um caráter introspectivo e é apontada como indicação de sucesso no processo de aprendizagem (NUNAN, 1999), pois é por seu intermédio que o aprendiz é levado a buscar dentro de si como ele se relaciona com o conteúdo a ser 
aprendido e com seu processo de aprendizagem como um todo. Outra área da consciência linguística amplamente debatida no âmbito do ensino comunicativo é a aquisição de competência pragmática. A discussão sobre diferenças culturais, suscitada implícita ou explicitamente, por intermédio da ação pedagógica planejada, pode tornar o aprendiz consciente das normas sociolinguísticas da língua e cultura estrangeiras, assim como de sua própria habilidade de se acomodar a elas (JUNG, 2001). Também na pragmática intercultural, a metaconversa e a reflexão que a retroalimenta, possibilitam o desenvolvimento da consciência linguística - dessa vez com relação à variabilidade cultural de aspectos como a expressão e interpretação de atos de fala literais e indiretos, da polidez e das funções discursivas desempenhadas pelos marcadores conversacionais, por exemplo.

O LC se relaciona com a consciência linguística como uma de suas vertentes - situada no domínio do poder (JAMES; GARRETT, 1991), a consciência linguística crítica também vê a língua como um fenômeno dinâmico. Porém, a consciência que busca não é de conhecimento simplesmente, mas de um processo socialmente situado: a conscientização nos termos Freirianos. Ao contrário das demais áreas da consciência linguística, que questionam a prescrição e promovem a descrição da língua em uso, a consciência linguística crítica vê a noção de propriedade, em substituição a de correção, apenas como uma forma de encobrir as razōes para se usar uma determinada variedade e toma a situação sociolinguística existente no discurso, não como natural, mas como veículo para perpetuação de uma ideologia. Para ela, o desenvolvimento de habilidades de comunicação não pode estar a serviço de necessidades econômicas, mas da subversão. Ou seja, a reflexão e a metaconversa fomentadas no LC precisam ir muito além do linguístico para serem capazes de localizar o aluno com relação ao não-dito - não ao implícito, mas ao silenciado: o público ao qual o texto serve e a ideologia que ele dissemina. Para Freire (1970, p. 75), a expressão da reflexão crítica é agente transformador, pois ela conduz à prática:

$\mathrm{Na}$ palavra há duas dimensões - reflexão e ação em uma intervenção tão radical que se uma delas é sacrificada - mesmo que em parte - a outra imediatamente sofre. Não há palavra verdadeira que não seja ao mesmo tempo uma prática. Então ao se proferir uma palavra verdadeira se transforma o mundo.

Os textos, orais, escritos e / ou multimodais, a que o aprendiz tem acesso, assim como as atividades que desempenham, devem, então, permitir não só 
a percepção da heterogeneidade dentro e entre as culturas mas também o desenvolvimento de um olhar distanciado e crítico com relação aos conteúdos informados pelo texto.

Vemos, então, que ambas as abordagens podem se servir da consciência linguística, promovendo a metaconversa e a reflexão, mas o fazem de modo totalmente diverso. A reflexão proposta no EC não contempla os anseios do LC e vice-versa, pois têm objetivos distintos. No EC ela está voltada para o processo de aprendizagem em si, e no LC ela serve ao desenvolvimento da consciência crítica. Ambas apontariam para um diagnóstico - mas no EC esse diagnóstico serviria para a solução de um problema ou conclusão de uma tarefa; no LC, contudo, esse diagnóstico buscaria desnudar um problema, o que permitiria um maior controle dessa situação problemática, objetivando a ação e a mudança. Poderíamos dizer, talvez, que no EC a reflexão estaria voltada para a provisão de soluções práticas; enquanto, para o LC, esta estaria voltada para uma problematização, uma tomada de consciência acerca de um estado de coisas de que se deve ter conhecimento sob pena de sua perpetuação.

Haveria aí uma evidente lacuna entre as duas abordagens, o que não implica, necessariamente, uma incompatibilidade. Muito pelo contrário, no que tange à reflexão e à metaconversa, as duas abordagens parecem ser complementares, bastando que a prática pedagógica sirva de elo entre suas demandas. Nesse caso, o aprendiz seria levado a diversos níveis de reflexão voltar-se-ia para si mesmo a fim de apoderar-se de seu processo de aprendizagem; voltar-se-ia para o texto a fim de dominar seus conteúdos semânticos, léxicosistêmicos, discursivos e pragmáticos; e voltar-se-ia, ainda, para o cenário sóciohistórico de sua interação com o texto, a fim de apoderar-se de sua própria história e de traçá-la de acordo com suas aspirações.

\section{Conciliando as duas abordagens - um exemplo da sala de aula de língua estrangeira}

Atividades comunicativas poderiam facilmente incorporar o letramento crítico, acrescentando-se a elas uma nova fase, na qual uma das etapas anteriores pudesse servir de insumo para a problematização essencial à crítica social. $\mathrm{Ou}$ seja, a metaconversa eliciada pela atividade poderia servir tanto para o desenvolvimento da competência comunicativa quanto para o desenvolvimento da consciência crítica - fins complementares, porém distintos. Então, em tese, o discurso alternativo transformador que se pretende dar-se-ia, também, em língua estrangeira, após o domínio do código. Na prática, no entanto, sabese que a produção de significados de grande complexidade em uma língua 
estrangeira demandaria condiçôes de aprendizagem que, em muito, se distanciam do cenário brasileiro atual, no que diz respeito à escola regular. Estaria, então, inviabilizado o letramento crítico para o ensino de línguas estrangeiras nas escolas? Acreditamos que não. Acreditamos que a flexibilidade, a transigência, a concessão e a criatividade serão elementos essenciais para a compatibilização das duas abordagens, como poderemos ver a seguir.

Como exemplo de possibilidade para a conciliação das duas abordagens, podemos citar uma atividade integrada para o desenvolvimento da comunicação oral e escrita, que, acreditamos, poderá servir de guia e inspiração para aqueles professores que desejam seguir as sugestóes das OCEM sem, contudo, abandonar os preceitos da abordagem comunicativa. Como o contexto de uso, e não a regra gramatical, é o ponto de partida para o EC, como sugerem Menezes de Souza e Monte-Mór (2006), propomos como insumo um texto oral autêntico, disponibilizado no link <http://www.youtube.com/ watch?v=AZuR0-Gyusw\&feature=related $>$ no site de hospedagem de vídeos on-line 'You Tube'. ${ }^{4} \mathrm{O}$ vídeo em questão retrata 'encontros de serviço' nos quais se dá uma brincadeira, popularmente conhecida como "pegadinha". Como parte da brincadeira, alguns turistas, após terem devidamente feito suas reservas, são surpreendidos pela falta de vagas ao se dirigirem à recepção de um hotel.

As etapas da aula (cf. QUADRO 2), cujo tema diz respeito à diversidade, mais especificamente, à conduta diante de problemas relacionados a viagens, seguem os procedimentos usuais de uma aula tipicamente comunicativa. No entanto, em vez de culminar com o enfoque de aspectos situacionais, linguísticos e discursivos do texto, como usualmente ocorre nessa abordagem, para atender às demandas do LC, essa atividade avança mais alguns passos no sentido de fomentar a reflexão crítica. Esta seria introduzida por um diálogo voltado para o questionamento das representaçóes no texto trazido para a sala de aula. Nesse caso, perguntas que buscam um posicionamento crítico, questionando o acesso a algumas comodidades da nossa sociedade (como a hospedagem em hotéis) podem ser feitas na língua-alvo e debatidas na língua materna, se necessário.

${ }^{4} \mathrm{O}$ vídeo foi removido do site do You Tube por violação dos termos de uso. No entanto, acreditamos que a atividade aqui proposta constitui apenas um exemplo de conciliação entre as duas abordagens e que a partir dela é possível elaborar outras atividades similares. 


\section{QUADRO 2}

Etapas de uma aula de língua estrangeira conciliando o EC e o LC: atividade de compreensão oral ${ }^{5}$

\begin{tabular}{|c|c|c|c|c|}
\hline & \multicolumn{4}{|c|}{ HOTEL CHECK IN } \\
\hline \multirow[t]{2}{*}{ Pré-escuta } & \multicolumn{2}{|c|}{$\begin{array}{l}\text { Ativação de esquemas de conteúdo } \\
\text { com relação ao tema "pegadinha" }\end{array}$} & \multicolumn{2}{|c|}{$\begin{array}{l}\text { Perguntas gerais sobre o que } \\
\text { os alunos sabem a respeito } \\
\text { dessas brincadeiras. }\end{array}$} \\
\hline & \multicolumn{2}{|c|}{$\begin{array}{l}\text { Ativação de esquemas formais e de } \\
\text { conteúdo com relação ao registro em hotéis }\end{array}$} & \multicolumn{2}{|c|}{$\begin{array}{l}\text { Check in } \\
\text { Make a reservation } \\
\text { Book a room } \\
\text { Booked up } \\
\text { Hotel receptionist/ manager }\end{array}$} \\
\hline \multirow{4}{*}{ Escuta } & $\begin{array}{l}\text { Contextos de uso } \\
\text { (perguntas que verifiquem } \\
\text { a compreensão da situação } \\
\text { apresentada no texto oral) }\end{array}$ & \multicolumn{3}{|c|}{$\begin{array}{l}\text { Qual é a situação? } \\
\text { Quem são os participantes? } \\
\text { Qual é o objetivo dos turistas? } \\
\text { Quais os problemas com os quais se deparam? } \\
\text { O que ganham os turistas vencedores? } \\
\text { O que devem fazer para vencer? }\end{array}$} \\
\hline & Habilidades comunicativas & \multicolumn{3}{|c|}{$\begin{array}{l}\text { Identificação de funções comunicativas } \\
\text { (pedir e fornecer informações; solicitar } \\
\text { confirmação de informações). } \\
\text { Identificação de recursos da linguagem verbal } \\
\text { para expressar assertividade. }\end{array}$} \\
\hline & \multirow[t]{2}{*}{ Aspectos linguísticos } & \multicolumn{2}{|c|}{ Formas interrogativas } & $\begin{array}{l}\text { Do you have a ...? } \\
\text { What's the...? } \\
\text { Are you sure it's...? }\end{array}$ \\
\hline & & \multicolumn{2}{|c|}{ Locuçôes adverbiais } & actually; definitely \\
\hline Pós-escuta & $\begin{array}{l}\text { Reflexão crítica } \\
\text { (perguntas que levem à } \\
\text { problematização da } \\
\text { situação apresentada } \\
\text { no texto oral) }\end{array}$ & \multicolumn{3}{|c|}{$\begin{array}{l}\text { O que é necessário para ser hóspede de } \\
\text { um hotel? } \\
\text { As pessoas no vídeo se parecem com as } \\
\text { pessoas que você conhece? Por quê? } \\
\text { Por que não? } \\
\text { Você já se hospedou em um hotel? } \\
\text { Que pessoas não frequentam hotéis? }\end{array}$} \\
\hline
\end{tabular}

\footnotetext{
${ }^{5}$ Esta atividade foi pensada a partir de sugestão contida nas OCEM para um "Diálogo entre recepcionista de hotel e hóspede estrangeiro sobre costumes locais" (MENEZES DE SOUZA; MONTE-MÓR, 2006, p. 121).
} 
Integrando habilidades orais e escritas, a atividade pode ter prosseguimento com a produção de uma carta para a direção do hotel, reclamando acerca do desaparecimento da reserva realizada. Com o seguimento da atividade, surge uma nova oportunidade para o desenvolvimento da consciência crítica por intermédio de uma metaconversa a ser realizada como insumo reflexivo adicional. A ação pedagógica planejada pode se voltar aí para a problematização de uma situação corriqueira em nossa sociedade: os problemas na prestação de serviços e o exercício do direito do cidadão de reclamar / contestar formalmente a ineficiência de tais serviços. Sabemos que poucas são as pessoas que exercem sua cidadania e demandam seus direitos de consumidor ou usuário de serviços, seja porque não acreditam na eficiência de sua reclamação, seja porque estão acostumados ao silenciamento por razões culturais e históricas. ${ }^{6}$ É comum que o cidadão se sinta inferiorizado, incapaz de fazer valer seus próprios direitos frente a instituições e / ou pessoas que ele considera superiores em suas capacidades. Nesse sentido, a carta de reclamação e a discussão que a fomenta podem resultar na produção de contradiscursos, necessários para o posicionamento do aluno na sociedade.

\section{QUADRO 3}

Etapas de uma aula de língua estrangeira conciliando o EC e o LC: atividade de produção escrita

\begin{tabular}{l|l|l}
\hline \multicolumn{2}{c}{ LETTER OF COMPLAINT } \\
\hline \multirow{4}{*}{ Pré-escrita } & $\begin{array}{l}\text { Contextos de uso } \\
\text { (perguntas que verifiquem } \\
\text { a compreensão sobre as } \\
\text { condições de produção do } \\
\text { texto a ser escrito) }\end{array}$ & $\begin{array}{l}\text { Quem são as pessoas envolvidas na situação } \\
\text { da carta de reclamação? } \\
\text { O que motivou a escrita da carta? } \\
\text { Qual o objetivo do escritor? }\end{array}$ \\
\cline { 2 - 3 } & $\begin{array}{l}\text { Reflexão crítica } \\
\text { problematização da } \\
\text { situação apresentada } \\
\text { no texto a ser escrito) }\end{array}$ & $\begin{array}{l}\text { Quem costuma reclamar formalmente } \\
\text { a respeito da qualidade / eficiência dos } \\
\text { serviços prestados por terceiros? } \\
\text { Quem silencia? Por que silencia? }\end{array}$ \\
\cline { 2 - 3 } & Aspectos discursivos & Layout e estrutura textual de cartas formais \\
\cline { 2 - 3 } & Aspectos linguísticos & Repertório vocabular de cartas de reclamação \\
\cline { 2 - 3 } & Aspectos sociolinguísticos & Polidez e assertividade nas cartas de reclamação \\
\hline
\end{tabular}

(continua)

\footnotetext{
${ }^{6}$ Agradecemos ao Prof. Dr. Lynn Mario Menezes de Souza, por sua contribuição (comunicação oral) com relação ao tema reclamação formal.
} 
(continuação)

\begin{tabular}{|c|c|}
\hline \multirow[t]{3}{*}{ Escrita } & $\begin{array}{l}\text { Em duplas, alunos preparam um plano textual para a carta, relatando os eventos } \\
\text { ocorridos com relação à reserva e ao registro no hotel e solicitam providências / } \\
\text { opinam / fazem sugestões para conduta futura dos funcionários do hotel. }\end{array}$ \\
\hline & Plano textual é desenvolvido em aula posterior. \\
\hline & Carta é editada em duplas e reescrita para publicação em sala \\
\hline Pós-escrita & $\begin{array}{l}\text { Como atividade de pós-escrita, as duplas podem trocar cartas entre si e uma } \\
\text { resposta, com um pedido de desculpas / oferecimento de compensação por } \\
\text { parte da administração do hotel, pode ser escrita em resposta à primeira carta. }\end{array}$ \\
\hline
\end{tabular}

\section{Considerações finais}

Com vistas a conciliar o letramento crítico a abordagens atuais para o ensino de uma língua estrangeira, como propõem as novas Orientações Curriculares para o Ensino Médio, tentamos aqui apontar algumas possibilidades nessa direção, discutindo possíveis pontos de contato entre o Ensino Comunicativo e o Letramento Crítico. Foram também levantados alguns pontos em que as duas abordagens se distanciam, o que não as torna, contudo, incompatíveis.

Como vimos, a noção de letramento (MENEZES DE SOUZA; MONTE-MÓR, 2006) parte de uma visão da disciplina do currículo escolar como um meio para a construção da cidadania, o que significaria capacitar o aluno a refletir criticamente sobre sua posição na sociedade - a preponderância da formação do indivíduo, como cidadão participante em sua comunidade, sobre os conteúdos curriculares. Partindo de Freire (1970), a aprendizagem da palavra do opressor poderia livrar o indivíduo de uma situação de marginalidade, tornando-o capaz de tomar posições e implementar ações que venham a transformar sua situação de inferioridade. A reflexão advinda a partir da consciência linguística crítica permite o empoderamento do indivíduo, preparando-o para o reconhecimento de seu papel na sociedade e para ações transformadoras com vistas à justiça social.

Porém, podemos atentar ao fato de que os objetivos do EC não excluem, em absoluto, as necessidades do LC. Muito pelo contrário, eles podem até mesmo ser vistos como complementares, pois a crítica social pressupõe o controle do código e a negociação de significados é uma prática social que, como tal, é potencialmente transformadora.

A preocupação legítima com o desenvolvimento da competência comunicativa dos aprendizes não impede a implementação de um currículo 
que vise à integração dos anseios do EC com os objetivos do LC, já que as duas abordagens mostram-se perfeitamente compatíveis e conciliáveis por meio do planejamento consciente e da ação pedagógica do professor. O QUADRO 4 ressalta os pontos de contato entre as duas abordagens e aponta as lacunas que precisam ser preenchidas por meio de um ensino crítico deliberadamente planejado para esse fim.

\section{QUADRO 4}

Pontos de contato e distanciamento entre as visões de aprendizagem do Ensino Comunicativo e do Letramento Crítico

\begin{tabular}{c|c}
\hline \multicolumn{2}{c}{ Visão de Aprendizagem } \\
\hline Ensino Comunicativo & Letramento Crítico \\
\hline \multicolumn{2}{c}{ Protagonismo do aprendiz } \\
\hline Heterogeneidade (valorização das diferenças) \\
\hline \multicolumn{2}{c}{ Autenticidade } \\
Gênero Textual \\
$\begin{array}{c}\text { Reflexão e metaconversa voltadas para } \\
\text { a solução de tarefas (problem-solving) }\end{array}$ & $\begin{array}{c}\text { Reflexão e metaconversa voltadas para } \\
\text { a problematização (problem-posing) }\end{array}$ \\
\hline
\end{tabular}

Vemos, então, que a noção de letramento crítico introduzida nas novas orientações curriculares implica uma profunda reformulação da prática pedagógica no Ensino Médio, assim como dos materiais utilizados para esse segmento. Em termos práticos, poderíamos talvez dizer que as novas orientações conduzem à seleção de textos que viabilizem a percepção da heterogeneidade e a elaboração de atividades contextualizadas, significativas para o aluno, que integrem diversas habilidades e que possam ser voltadas para a reflexão crítica. $\mathrm{O}$ ensino da língua torna-se, assim, um meio para atingir ambos os objetivos: o desenvolvimento da competência comunicativa do aprendiz e a formação do indivíduo cidadão. A ação pedagógica, exercida de forma consciente e deliberada, firma-se, então, como o elo necessário para se alcançar esses objetivos. 


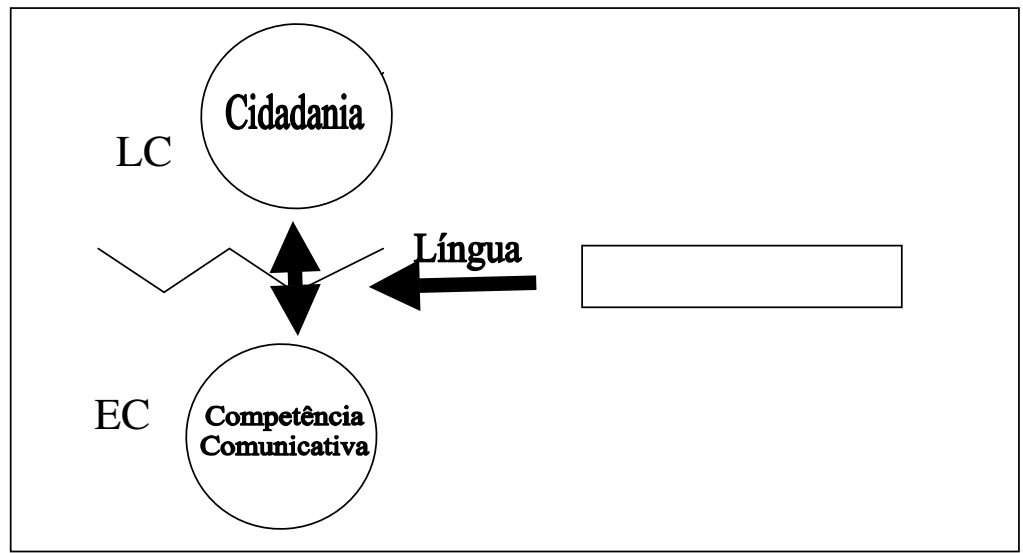

\section{Referências}

ALFORD, J. Learning language and critical literacy: adolescent ESL students. Journal of Adolescent \& Adult Literacy, v. 45, n. 3, p. 238-242, 2001.

ALMEIDA FILHO, J. C. P. O ensino de línguas no Brasil de 1978. E agora? Revista Brasileira de Linguistica Aplicada, v. 1, n. 1, p. 15-29. 2001.

ANDREOTTI, V. O. A postcolonial reading of contemporary discourses related to the global dimension in education in England. 2006. $229 \mathrm{f}$. Tese (Doutorado) University of Nottingham, Inglaterra, 2006.

AUSTIN, J. L. How to do things with words. Oxford: Oxford University Press, 1962 (1975).

BAX, S. The role of genre in language syllabus design: the case of Bahrain. International Journal of Educational Development, v. 26, p. 315-328, 2006.

BHATIA, V. K. Analysing Genre. Londres: Longman,1993.

BIBLER, V. S. M. M. Bakhtin, or the Poetics of Culture. Moscow: Politizdat Press, 1991. Apud SAVIGNON, S. J. Beyond communicative language teaching: what's ahead? Journal of Pragmatics, v. 39, p. 207-220, 2007.

BOURDIEU, P. Razóes práticas: sobre a teoria da ação. Campinas, SP: Papirus, 1996.

BOXER, D. Applying sociolinguistics: domains and face-to-face interaction. Amsterdam: John Benjamins, 2002.0

CELCE-MURCIA, M.; OLSHTAIN, E. Discourse and language teaching: a guide for language teachers. Cambridge: Cambridge University Press, 2000. 
CERVETTI, G.; PARDALES, M. J.; DAMICO, J. S. A tale of differences: comparing the traditions, perspectives and educational goals of critical reading and critical literacy. Reading Online, v. 4, n. 9, 2001. Disponível em: <http:// www.readingonline.org/articles/art_index.asp?HREF=articles/cervetti/ index.html>. Acesso em: 30 mar. 2007.

COPE, B; KALANTZIS, M. Multiliteracies: literacy learning and the design of social futures. Londres: Routledge, 2000.

CRAWFORD, J. The role of materials in the language classroom: finding the balance. In: RICHARDS, J. J.; RENANDYA, W. A. (Ed.). Methodology in language teaching. Cambridge: Cambridge University Press, 2002. p. 80-90.

CRAWSHAW, R. Intercultural awareness as a component of HE Modern Language courses in the UK, 2005. Disponível em: <http://www.llas.ac.uk/ resources/goodpractice. aspx? resourceid=2303>. Acesso em: 18 out. 2006.

ELLIS, R. Instructed second language acquisition: A literature review. Wellington: The Research Division of the New Zealand Ministry of Education, 2005. Disponível em: <www.minedu.govt.nz>. Acesso em: 20 ago. 2007.

FREIRE, P. Pedagogia do oprimido. Rio de Janeiro: Paz e Terra, 1970.

HALLIDAY, M. A. K. Language as social semiotic: the social interpretation of language and meaning. London: Edward Arnold, 1978.

HAMMOND, J.; DEREWIANKA, B. Genre. In: CARTER, R.; NUNAN, D. (Ed.). Teaching English to speakers of other languages. Cambridge: Cambridge University Press, 2001. p. 186-193.

HAWKINS, E. W. Foreign language study and language awareness. Language Awareness, v. 8.3, n. 4, 1999. p. 124-142.

HYMES, D. Models of the interaction of language and social life. In: GUMPERZ, J. J.; HYMES, D. (Ed.). Directions in sociolinguistics: the ethnography of communication. New York: Holt, Rinehart \& Winston, 1972. p. 35-71.

JAMES, C.; GARRETT, P. (Ed.). Language awareness in the classroom. London: Longman, 1991.

JOHNS, A. M. et. al. Crossing the boundaries of genre studies: commentaries by experts. Journal of Second Language Writing, v. 15, p. 234-249, 2006.

JORDÃO, C. M. Uma breve história da leitura no século xx, ou de como se podem calar as nativas. Revista de Letras, v. 5, 2002. Disponível em: <http:// www.dacex.ct.utfpr.edu.br/clarisse5.htm>. Acesso em: 20 ago. 2007.

JUNG, J. Issues in Acquisitional pragmatics. Working papers in TESOL \& Applied Linguistics. 2001. Disponível em: <http://www.tc.columbia.edu/academic/ tesol/webjournal>. Acesso em ago. 2002. 
LANKSHEAR, C.; KNOBEL, M. New literacies: changing knowledge and classroom learning. Buckingham: Open University Press, 2003.

McDONOUGH, J.; SHAW, C. Materials and methods in ELT: a teacher's guide. Oxford: Blackwell, 2003.

McLAUGHLIN, M.; DeVOOGD, G. L. Critical literacy: Enhancing students' comprehension of text. New York: Scholastic, 2004.

MENEZES DE SOUZA, L. M. T.; MONTE-MÓR, W. M. Orientaçôes curriculares para o ensino médio: linguagens, códigos e suas tecnologias conhecimentos de línguas estrangeiras. Brasília: Ministério da Educação / Secretaria de Educação Básica, 2006. Disponível em: <http://portal.mec.gov.br/ seb/arquivos/pdf/book_volume_01_internet.pdf>. Acesso em: 6 fev. 2008.

MORIN, E. A cabeça bem-feita: repensar a reforma - reformar o pensamento. Rio de Janeiro: Bertrand Brasil, 2000.

NORTON, B. Critical literacy and international development. Critical Literacy: Theories and Practices, v. 1, n. 1, p. 6-15, 2007. Disponível em: <http:// www.criticalliteracy.org.uk/images/journal/v1 issue1/norton.pdf >. Acesso em: 22 maio 2008.

NUNAN, D. Second language teaching and learning. Boston, MA: Heinle \& Heinle, 1999.

PALTRIDGE, B. Genre and the language learning classroom. Ann Arbor: the University of Michigan Press, 2001.

RICHARDS, J. C.; RODGERS, T. S. Approaches and methods in language teaching. New York: Cambridge University Press, 1986.

SAVIGNON, S. J. Communicative language teaching for the twenty-first century. In: CELCE-MURCIA, M. (Ed.). Teaching English as a second or foreign language. Boston, MA: Heinle \& Heinle, 2001. p. 13-28.

SAVIGNON, S. J. Beyond communicative language teaching: what's ahead? Journal of Pragmatics, v. 39, p. 207-220, 2007.

SEARLE, J. R. Speech act: an essay in the philosophy of language. Cambridge: Cambridge University Press, 1969.

SEARLE, J. R. What is a speech act? In: SEARLE, J. R. (Ed.). The philosophy of language. London: Oxford University Press, 1971. p. 39-53.

SILVER, D. Multimedia, multilinearity, and multivocality in the hypermedia classroom. Computers \& Texts, v. 14, 1997. Disponível em: <http://users.ox.ac.uk/ -ctitext2/ publish/comtxt/ct14/silver.html> Acesso em: 4 jun. 2008.

SOKOLIK, M. Computers in language teaching, In: CELCE-MURCIA, M. (Ed.). Teaching English as a second or foreign language. Boston, MA: Heinle \& Heinle, 2001. p. $477-488$. 
SVALBERG, A. M-L. Language awareness and language learning. Language Teaching, v. 40, p. 287-308, 2007.

SWALES, J. Genre Analysis: English in Academic and Research Settings. Cambridge: Cambridge University Press, 1990.

TOCALLI-BELLER, A.; SWAIN, M. Reformulation: The cognitive conflict and L2 learning it generates. International Journal of Applied Linguistics, v. 15, n. 1, p. 5-28, 2005.

WIDDOWSON, H. The roles of teacher and learner. ELT Journal, v. 41, n. 2, p. 83-88, 1987.

Recebido em 08/05/09. Aprovado em 06/08/09. 